Brief Report

\title{
Community-based household survey to identify disability burden and health-related quality of life following road traffic accidents in Ujjain, India
}

\author{
Aditya Mathur ${ }^{1}$, Love Mehra ${ }^{1}$, Ashish Pathak ${ }^{1,2,3 *}$ \\ ${ }^{1}$ Department of Paediatrics, R. D. Gardi Medical College, Ujjain 456006, India; dr.adityamathur121@gmail.com \\ (A.M), lovemehra2000@gmail.com (L.M.) \\ ${ }^{2}$ Global Health-Health Systems and Policy: Medicines, Focusing Antibiotics, Department of Public Health \\ Sciences, Karolinska Institutet, Stockholm, Sweden; ashish.pathak@ki.se \\ ${ }^{3}$ Department of Women and Children's Health, International Maternal and Child Health Unit, Uppsala \\ University, Uppsala SE-751 85, Sweden; ashish.pathak@kbh.uu.se \\ *Correspondence: ashish.pathak@kbh.uu.se; Tel.: +91-9302239899
}

\begin{abstract}
The objective of the study was to report the health-related quality of life (HRQOL) following road traffic accidents (RTAs) among children. A community-based survey using EuroQol five-dimension questionnaire (EQ-5D-5L) in Hindi was used to collected data from community. The survey included 2620 households from urban and rural areas of Ujjain, India. From these households 229 children aged 5-18 years with a history of RTA in the last 1 year were identified, with $27 \%, 63 \%$, and $10 \%$ children reporting mild, moderate, and severe injury based on length of hospitalization. Motorcycles, bicycles, and pedestrians constituted most RTAs. Helmet use was low (12\%). EQ-5D-5L revealed that the most severe and extreme problem was pain and discomfort, whereas the least severe problem was usual activity and self-care. The most common $(65 \%)$ injuries were either abrasion or fracture and dislocation. EQ-5D-5L severity index was maximum (mean 72) for lower extremity injuries. The results of the present study highlight the ability and requirement for quality of life measurement using EQ-5D-5L among children post-RTA.
\end{abstract}

Keywords: Children; adolescents; post-road traffic accidents; EQ-5D-5L; disability burden; health-related quality of life

\section{Introduction}

In 2107, road traffic accidents (RTAs) were the eleventh leading cause of death globally [1]. All injuries including RTA-related deaths are avertable, yet they cause death and disabilities at all ages [2]. In India, deaths due to RTA are under-reported [3]. Despite this, RTAs are the leading cause of mortality among the 15-39-years age group in India [2]. For each reported child death due to RTA in low- and middle-income countries, an estimated 254 children need hospitalization and 4 have permanent disability [4]. Disabilities in children can lead to destitution for the family and change the life of the affected child and family. Major RTAs lead to missed school and education, possible future unemployment, social rejection, and psychological stress [2]. There is a paucity of global and Indian community-based studies reporting the RTA disability burden and health-related quality of life (HRQOL) following RTA in children [5]. In the absence of data on RTA and the resulting disabilities, policymakers cannot plan appropriate resource allocations to mitigate RTA [1]. Therefore, the objective of this study was to report the HRQOL following RTA among children to plan future resource allocation for their disability rehabilitation.

\section{Materials and Methods}




\subsection{Study Site and Settings}

This cross-sectional, community-based survey was conducted from January 2020 to March 2020 in seven villages and ten urban slums of Ujjain district and city, respectively using the World Health Organization injury survey methodology [6]. After listing, mapping, and house-to-house survey of 2620 households with 6898 children, 229 children and adolescents between 5 and 18 years of age having a history of RTA in the past one year were identified.

\subsection{Sample Size}

Sample size calculation was performed using Stata 12 (StataCorp., College Station, TX, USA), based on an Indian study that reported 15\% participants with a severe injury score and a third of participants with a mild injury severity score [5]. Thus, sample size calculation was performed to detect at least $15 \%$ difference around a proportion of 0.15 , with a power of 90 , and two-sided alpha of 0.05 . The estimated minimum required sample size was 174 . Assuming a $20 \%$ refusal rate for participation, we increased the sample size by a similar proportion to $209(174 \times 0.2)$.

\subsection{Data Collection and Management}

The data on the details of RTAs in the last one year such as the type of accidents, vehicle details, and duration of hospitalization were collected on forms and entered in Epi info 7 (7.1.3, CDC Atlanta, Georgia, USA) after coding. The analysis was performed using Stata 12 (StataCorp., College Station, TX, USA).

\subsection{Outcome Measure}

HRQOL was measured using the self-administered five-level Hindi version of the EuroQol five dimensions questionnaire (EQ-5D-5L) [7]. The Hindi version of the EQ-5D-5L was translated by the EuroQol. The face-to-face interview version of EQ-5D-5L was used for children who were unable to complete the self-administered version $(n=55)$. Because EQ-5D-5L is not validated for Indian children, it was scored in double for the face-to-face interview version. The inter-rater reliability coefficient for this subsample was excellent (intraclass correlation coefficient $($ ICC $)=0.86-0.92$ ). The 5D component of the EQ-5D-5L consists of five distinct dimensions: mobility, self-care, usual activities, pain or discomfort, and anxiety or depression, whereas the $5 \mathrm{~L}$ component consists of five levels of problems ranging from no problem to extreme problem [7]. Children were asked to fill only one level on each domain ( 1 to 5 ). The digits on each domain can be combined to form a five-digit number ranging from 11111 to 55555. In the present study, the EQ-5D-5L results were interpreted by the sum score severity index [8]. The severity index was computed by the summation of the levels in each dimension of EQ-5D-5L, subtracting 5 points and multiplying the result by 5 . This resulted in a sum score severity index in a 0-100 range, where more points mean more severity [8]. This sum score severity index was a measure of the health outcome and reflected the child or adolescent's own judgment of health outcome [8]. The sum score index mean along with its $95 \%$ confidence intervals (CI) were reported. Injury severity was measured using length of stay (LOS) in hospital, a surrogate measure of injury severity and resource use among injury survivors [9]. LOS was categorized as mild (LOS 0-1 day), moderate (LOS 2-7 days), or severe (LOS 8+ days) [10].

\subsection{Ethical Approval}

The Institutional Ethics Committee approved the study (approval number 94-A/2019).

\section{Results}


Of the 229 children in the study, $167(73 \%)$ were boys, and $62(27 \%)$ were girls. The mean ( \pm SD) age of children was $12( \pm 4)$ years [boys $12( \pm 4)$ and girls $11( \pm 4)$ ]. A total of $62(27 \%)$ children reported mild injury, $144(63 \%)$ moderate, and $23(10 \%)$ severe injury, based on LOS.

At the time of the RTA, the child or adolescent was riding a motorcycle in $37 \%(n=84)$, bicycle in $21 \%(n=49)$, was a pedestrian in $21 \%(n=49)$, and was a motorbike or bicycle pillion rider in $20.5 \%$ $(n=47)$ of cases. The RTA was caused by a duppatta (long scarf) in a majority of female pillion riders $(n=15 / 20)$. The causes of RTAs included collision with an object $(n=141,51 \%)$ or slipping of the victim or perpetrator's vehicle $(n=88,39 \%)$. The RTA was caused due to collision with a four-wheeler (car, truck, or van) $(n=60 ; 29 \%)$ or motorcycle $(n=51,22 \%)$. Helmet use was low $(n=$ $10 / 84 ; 12 \%$ ) among the motorcycle users. The disability level and dimensional distribution according to EQ-5D-5L exhibits that most children had level 2 (38\%) (slight problem) or level $3(26 \%)$ mobility (moderate problem). Most severe (level 4) and extreme (level 5) problems were seen in the pain or discomfort dimension (Table 1), whereas least problems (levels 1 and 2) were seen in usual activity and self-care.

Table 1 EuroQol five dimensions questionnaire (EQ-5D-5L) frequencies and proportions reported by dimension and level

\begin{tabular}{llllll}
\hline & $\begin{array}{l}\text { Mobility } \\
\mathbf{n = 2 2 9}(\mathbf{\%})\end{array}$ & $\begin{array}{l}\text { Self-care } \\
\mathbf{n = 2 2 9}(\mathbf{\%})\end{array}$ & $\begin{array}{l}\text { Usual } \\
\text { activities } \\
\mathbf{n = 2 2 9}(\mathbf{\%})\end{array}$ & $\begin{array}{l}\text { Pain/ } \\
\text { discomfort } \\
\mathbf{n = 2 2 9}(\mathbf{\%})\end{array}$ & $\begin{array}{l}\text { Anxiety/ } \\
\text { depression } \\
\mathbf{n = 2 2 9}(\%)\end{array}$ \\
\hline Level 1 (No problems) & $142(62)$ & $156(68)$ & $165(72)$ & $92(40)$ & $133(58)$ \\
Level 2 (Slight problems) & $43(19)$ & $34(15)$ & $23(10)$ & $57(25)$ & $60(26)$ \\
Level 3 (Moderate problems) & $25(11)$ & $23(10)$ & $18(8)$ & $48(21)$ & $18(8)$ \\
Level 4 (Severe problems) & $11(5)$ & $9(4)$ & $14(6)$ & $18(8)$ & $14(6)$ \\
Level $\mathbf{5}$ (Extreme problems) & $8(3)$ & $7(3)$ & $9(4)$ & $14(6)$ & $4(2)$ \\
\hline
\end{tabular}

$\%$-Column percentage

The distribution of type of injuries and their anatomical location is illustrated in Table 2.

Table 2 The distribution of type of injuries and their anatomical site in 229 children post road traffic accidents identified in the study

\begin{tabular}{|c|c|c|c|c|c|c|c|}
\hline & $\begin{array}{c}\text { Total } \\
\text { n = } 615 \\
(\%)\end{array}$ & $\begin{array}{c}\text { Abrasions } \\
\text { n }=271 \\
(\%)\end{array}$ & $\begin{array}{c}\text { Fractures } \\
\text { and } \\
\text { dislocations } \\
\mathrm{n}=130(\%)\end{array}$ & $\begin{array}{c}\text { Cuts, } \\
\text { contusio } \\
\mathrm{n} \text { and } \\
\text { laceratio } \\
\mathrm{n} \\
\mathrm{n}=146 \\
(\%)\end{array}$ & $\begin{array}{c}\text { Muscular } \\
\text { injury } \\
n=32(\%)\end{array}$ & $\begin{array}{c}\text { Internal } \\
\text { organ } \\
\text { injury } \\
n=25 \\
(\%)\end{array}$ & $\begin{array}{c}\text { Crush } \\
\text { injury and } \\
\text { amputatio } \\
n \\
n=11(\%)\end{array}$ \\
\hline $\begin{array}{l}\text { Head, face, and } \\
\text { neck }\end{array}$ & $85(14)$ & $29(11)$ & $2(1)$ & $34(23)$ & $2(6)$ & $17(68)$ & $1(9)$ \\
\hline $\begin{array}{l}\text { Shoulder, back } \\
\text { and abdomen }\end{array}$ & $35(5)$ & $7(2)$ & $10(8)$ & $6(4)$ & $3(10)$ & $8(32)$ & $1(9)$ \\
\hline Upper extremities & $127(21)$ & $62(23)$ & $26(20)$ & $27(19)$ & $9(28)$ & $0(0)$ & $3(27)$ \\
\hline Lower extremities & $368(60)$ & $173(64)$ & $92(71)$ & $79(54)$ & $18(56)$ & $0(0)$ & $6(55)$ \\
\hline
\end{tabular}

$\%$-Column percentage 
The two most common injuries following RTA were abrasions along with fracture and dislocation, whereas the least common were crush or nerve injuries and amputation.

Table 3 illustrates the mean and $95 \% \mathrm{CI}$ of the severity index. The maximum mean value of severity index was for lower limb injuries (mean 72), followed by shoulder, back, and abdomen (mean 34). The mean severity indices for mild, moderate, and severe disease based on LOS were 18, 22, and 68, respectively.

Table 3 The mean and its 95\% confidence interval of sum-score severity index according to the anatomical site of injury post road traffic accident

\begin{tabular}{lccc}
\hline & RTI & \multicolumn{2}{c}{ Severity index } \\
\hline & $\mathbf{n = 6 1 5}$ & Mean & $\mathbf{9 5 \% ~ C I ~}$ \\
\cline { 2 - 4 } Lower extremity & 85 & 72 & $66-77$ \\
Upper extremity & 35 & 27 & $20-34$ \\
Head, face, and neck & 127 & 27 & $18-36$ \\
Shoulder, back, and abdomen & 368 & 34 & $0-68$ \\
\hline
\end{tabular}

RTI-Road Traffic Injuries; CI-Confidence Interval

\section{Discussion}

To the best of our knowledge, this is the first Indian pediatric study reporting HRQOL as measured by EQ-5D-5L from a community-based survey. The EQ-5D-5L instrument has been used in some studies performed in adults to assess QOL [10]. The present study proves that RTAs lead to loss of health and human capital among children, which could be averted with improved safety and prevention programs and ensuring access to care resources [1]. The Government of India has increased fund allocation toward "Road Safety" [3]. However, research funds for identifying evidence-based road safety interventions must be increased to reduce the Indian RTA burden.

In the present study RTAs exhibited a male predilection, which is a universal phenomenon because of their differential exposure to risk and risk-taking behavior. An additional reason could be the patriarchal nature of Indian society where boys are allowed more autonomy compared with girls [11].

In the present study, motorbikes were the most common cause of RTA, followed by bicycle pillion riders. Large Indian data also points to similar injury patterns in children [3]. Injury among two-wheeler pillion riders is also typically observed in a study among adults in New Delhi [12]. Use of duppata by females has been a known risk factor for RTAs in the Indian subcontinent [13]. Helmet non-use among teenage motorcyclists increases the risk of severe head injury by about 15-33 times [4]. Between 3\% and 15\% of all injured children in RTA are child cyclists [4]. Pedestrian children aged between 5 and 14 years have the highest risk of injury in low- and middle-income countries and account for $30 \%-40 \%$ of all child RTAs $[4,14]$.

The psychological consequences of RTAs in children is a necessary but often overlooked consideration but are rarely done [15]. The overall prevalence of post-traumatic stress disorder in children is at present estimated at just less than $10 \%$ [15]. The prevalence of anxiety or depression was low in the present study probably due to good coping mechanisms, social support, and time since injury as the study used a recall period of one year [16]. In a study among Vietnamese adults, the highest mean EQ-5D-5L index was observed for hand injuries, whereas in the present study, it was highest for lower limb injuries [17].

The study has certain limitations. The EQ-5D-5L also has a visual analog scale (VAS) that records the overall self-rated health status on the day of interview [7]. VAS was not used because children found it difficult to interpret. As the EQ-5D-5L is not validated in India we reported the ICC for a subset of children. 


\section{Conclusions}

The study highlights that EQ-5D-5L can be used to monitor HRQOL in children post-RTA. The results of EQ-5D-5L correlate with the injury severity. EQ-5D-5L severity index can prospectively monitor HRQOL in children that are victims of RTA.

Author Contributions: Conceptualization, AP; methodology, AP, AM software, AM, LM, AP; validation, AM, LM, AP; formal analysis, AM, AP; investigation, AM, LM, AP.; resources, AP.; data curation, AM, LM, writing - original draft preparation, AP.; writing - review and editing, AM, LM, AP; visualization, AM, LM, AP supervision, AP.; project administration, AP.; funding acquisition, AP. All authors have read and agreed to the published version of the manuscript.

Funding: This research was funded by Indian Council of Medical Research (ICMR), New Delhi, India, grant number 2013-1253 to Ashish Pathak.

Acknowledgments: The authors thank all the study participants for participating in the study. The authors thank the management and the RD Gardi Medical College, Ujjain for their support and encouragement.

Conflicts of Interest: The authors declare no conflict of interest. The funders had no role in the design of the study; in the collection, analyses, or interpretation of data; in the writing of the manuscript, or in the decision to publish the results.

\section{References}

1. James, S.L.; Castle, C.D.; Dingels, Z.V.; Fox, J.T.; Hamilton, E.B.; Liu, Z.; NL, S.R.; Sylte, D.O.; Henry, N.J.; LeGrand, K.E., et al. Global injury morbidity and mortality from 1990 to 2017: Results from the global burden of disease study 2017. Inj Prev 2020.

2. Karan, A.; Negandhi, H.; Nair, R.; Sharma, A.; Tiwari, R.; Zodpey, S. Size, composition and distribution of human resource for health in india: New estimates using national sample survey and registry data. BMJ Open 2019, 9, e025979.

3. India State-Level Disease Burden Initiative Road Injury, C. Mortality due to road injuries in the states of India: The global burden of disease study 1990-2017. Lancet Public Health 2020, 5, e86-e98.

4. Peden M, O.K., Ozanne-Smith J, Hyder AA, Branche C, Rahman F, Rivara F and Bartolomeos K. Who-world report on child injury prevention. WHO Press: Geneva, Switzerland, 2008.Available from https://apps.who.int/iris/bitstream/handle/10665/43851/9789241563574_eng.pdf;jsessionid=632407C BB1DE8CCB6E1DBA720E5D3538? sequence $=1$

5. Jagnoor, J.; Prinja, S.; Christou, A.; Baker, J.; Gabbe, B.; Ivers, R. Health-related quality of life and function after paediatric injuries in India: A longitudinal study. Int J Environ Res Public Health 2017, 14.

6. WHO. Training educating and advancing collaboration in health on violence and injury prevention manual. Available from: Whqlibdoc.Who.Int/publications/2012/9789241503464_eng.Pdf?Ua=1. World Health Organization: Geneva, Switzerland., 2012.

7. Herdman, M.; Gudex, C.; Lloyd, A.; Janssen, M.; Kind, P.; Parkin, D.; Bonsel, G.; Badia, X. Development and preliminary testing of the new five-level version of EQ-5D (EQ-5D-5L). Qual Life Res 2011, 20, 1727-1736. 
8. Ferrer-Pena, R.; Calvo-Lobo, C.; Aiguade, R.; Fernandez-Carnero, J. Which seems to be worst? Pain severity and quality of life between patients with lateral hip pain and low back pain. Pain Res Manag 2018, 2018, 9156247.

9. Newgard, C.D.; Fleischman, R.; Choo, E.; Ma, O.J.; Hedges, J.R.; McConnell, K.J. Validation of length of hospital stay as a surrogate measure for injury severity and resource use among injury survivors. Acad Emerg Med 2010, 17, 142-150.

10. Jagnoor, J.; Prinja, S.; Nguyen, H.; Gabbe, B.J.; Peden, M.; Ivers, R.Q. Mortality and health-related quality of life following injuries and associated factors: A cohort study in Chandigarh, north India. Inj Prev 2019.

11. Batra R.; Reio T.G., J. Gender inequality issues in India. Advances in Developing Human Resources 2016, Volume: 18 88-101.

12. Siddiqui, S.M.; Sagar, S.; Misra, M.C.; Gupta, A.; Crandall, M.; Swaroop, M. Patterns of injury among motorized two-wheeler pillion riders in New Delhi, India. J Surg Res 2016, 205, 142-146.

13. Minhas, M.S.; Sangani, M.M.; Mehmood, K.; Bhatti, A.; Mughal, A.; Kumar, R. Dupatta (long scarf) related injuries in female pillion riders in Karachi Pakistan. J Pak Med Assoc 2016, 66, 1458-1461.

14. Pal, R.; Ghosh, A.; Kumar, R.; Galwankar, S.; Paul, S.K.; Pal, S.; Sinha, D.; Jaiswal, A.K.; Moscote-Salazar, L.R.; Agrawal, A. Public health crisis of road traffic accidents in India: Risk factor assessment and recommendations on prevention on the behalf of the academy of family physicians of India. J Family Med Prim Care 2019, 8, 775-783.

15. Olofsson, E.; Bunketorp, O.; Andersson, A.L. Children and adolescents injured in traffic--associated psychological consequences: A literature review. Acta Paediatr 2009, 98, 17-22.

16. Stallard, P.; Velleman, R.; Langsford, J.; Baldwin, S. Coping and psychological distress in children involved in road traffic accidents. Br J Clin Psychol 2001, 40, 197-208.

17. Vu, H.M.; Dang, A.K.; Tran, T.T.; Vu, G.T.; Truong, N.T.; Nguyen, C.T.; Doan, A.V.; Pham, K.T.H.; Tran, T.H.; Tran, B.X., et al. Health-related quality of life profiles among patients with different road traffic injuries in an urban setting of Vietnam. Int J Environ Res Public Health 2019, 16. 